\title{
Desain Evaluasi Program Pelatihan Guru Fisika Profesional
}

\author{
Rahmat Rizal $^{1 *}$, Ernita Susanti ${ }^{1}$, Dwi Sulistyaningsih ${ }^{1}$, Deni Moh Budiman ${ }^{2}$ \\ ${ }^{1}$ Pendidikan Fisika, Universitas Siliwangi, Tasikmalaya, Indonesia \\ ${ }_{2}^{2}$ Pendidikan Guru Sekolah Dasar, STKIP Sebelas April, Sumedang, Indonesia \\ *e-mail korespondensi: rahmatrizal@unsil.ac.id
}

(masuk: 16-05-2020; revisi: 11-06-2020; diterima: 20-06-2020)

\begin{abstract}
Abstrak: Keberhasilan pendidikan tidak bisa terlepas dari peran penting guru. Guru perlu mengembangkan diri untuk menjadi profesional dalam memberikan layanan pendidikan kepada siswa melalui optimalisasi diri dengan sejumlah kompetensi yaitu kompetensi kepribadian, pedagogik, sosial, dan profesional. Diperlukan adanya suatu stimulus yang memfasilitasi tercapainya profesionalitas guru, salah satunya adalah dengan program kegiatan pelatihan guru profesional. Kegiatan pelatihan sejenis ini perlu dievaluasi agar dapat memberikan manfaat yang efektif dan signifikan. Salah satu bentuk evaluasi program pelatihan yang dapat diimplementasikan adalah model evaluasi empat level Kirkpatrick yang setiap levelnya merepresentasikan sebuah sekuen dari setiap tahapan untuk mengevaluasi program. Empat level evaluasi tersebut terdiri dari: Level 1Reaction (Reaksi), Level 2- Learning (Pembelajaran), Level 3- Behavior (Perilaku), dan Level 4- Results (Hasil/Dampak). Kegiatan evaluasi dilakukan secara sekuen pada setiap level, karena setiap level memberi dampak pada level berikutnya. Dengan adanya evaluasi menggunakan model ini diharapkan bisa memberikan deskripsi kualitatif yang komprehensif dan dapat digunakan sebagai bahan pertimbangan kepada penyelenggara dan stakeholder dalam menindaklanjuti program selanjutnya.
\end{abstract}

Kata kunci: Desain evaluasi program, Guru Profesional, Pelatihan

\section{PENDAHULUAN}

Mengingat pentingnya pendidikan, pemerintah terus berupaya untuk mengoptimalkan kegiatan pendidikan dengan menyediakan dana APBN sekurang-kurangnya 20\% dari anggaran keseluruhan. Anggaran dana pendidikan yang berlimpah selayaknya diimbangi dengan peningkatan kualitas sumber daya yang terlibat dalam lembaga pendidikan.

Keberhasilan pendidikan di sekolah sangat tidak bisa terlepas dari peran penting guru (Rizali, 2009:12-13). Guru adalah pendidik profesional dengan tugas utama mendidik, mengajar, membimbing, mengarahkan, melatih, menilai, dan mengevaluasi siswa pada pendidikan anak usia dini, pendidikan dasar, dan pendidikan menengah. Guru sebagai pelaksana di setiap satuan pendidikan didorong untuk mengembangkan diri dengan sejumlah keterampilan abad 21 sebagai penyesuaian terhadap perkembangan zaman (Makiyah, 2019). Guru perlu mengembangkan diri untuk menjadi profesional dalam memberikan layanan pendidikan kepada siswa baik secara kognitif, afektif, dan psikomotor serta melaksanakan tugas dan tanggung jawabnya dengan sukses (Norlander, 2009). Salah satu bentuk pelayanan dalam pengembangan siswa pada pembelajaran fisika adalah dengan menyelenggarakan kegiatan eksperimen yang bersifat inovatif. Contohnya adalah penentuan koefisien viskositas air dengan aliran kapiler (Sulistyaningsih dkk, 2019)

$$
\text { Peraturan Menteri Pendidikan }
$$

Nasional No 16 tahun 2007 telah memaparkan bahwa guru profesional 
dibangun dengan empat jenis kompetensi yang meliputi kompetensi kepribadian, kompetensi pedagogik, kompetensi profesional, dan kompetensi sosial. Keempat kompetensi ini perlu bersinergi satu dengan yang lain sehingga menjadi bagian yang terintegrasi pada diri seorang Guru. Kehadiran revolusi industri 4.0 yang sarat akan teknologi maka kompetensi guru perlu diperbarui dengan literasi digital agar dapat menciptakan pembelajaran yang bermakna sesuai dengan esensi dari pendidikan IPA (Rizal, 2019; Rizal dan Ridwan, 2019; Susanti dkk., 2019)

Secara global, kondisi kompetensi guru secara profesional masih belum sesuai dengan yang diharapkan. Rekapitulasi nasional hasil Uji Kompetensi Guru (UKG) tahun 2015 yang mengukur kompetensi pedagogik dan kompetensi profesional menunjukkan nilai rata-rata 53,02. Nilai ini masih belum memenuhi Standar Kompetensi Minimum (SKM) yang telah ditetapkan yaitu 5,50. (Kemendikbud, 2015).

Beberapa penelitian menunjukkan bahwa secara khusus guru-guru fisika di lapangan belum menerapkan proses pembelajaran sesuai dengan standar pembelajaran untuk fisika (Rizal, 2011; Rizal, 2019). Para guru belum siap untuk dapat menerapkan kurikulum 2013 pada setiap kegiatan pembelajaran (Susanti dkk., 2015). Padahal kompetensi dalam memberikan pembelajaran merupakan kompetensi pedagogik yang harus sudah dikuasai oleh guru profesional dimana guru harus mampu menyelenggarakan pembelajaran yang bermakna agar siswa dapat mengonstruksi pengetahuannya sendiri dengan keterampilan yang sudah dimiliki (Mahmudah, 2019).

Untuk mengatasi permasalahan kompetensi guru seperti yang telah dipaparkan maka dibutuhkan pelatihan, peningkatan, dan pengembangan (Rizal dkk, 2020). LPTK, P4TK, dan lembaga pendidikan lainnya menginisiasi untuk mengadakan sejumlah pelatihan dengan konten dan durasi bervariatif untuk membekali para guru dengan kompetensi yang dibutuhkan agar menjadi guru profesional (Budiman, 2018). Namun, pada umumnya kegiatan pelatihan ini belum dievaluasi secara sistematis dan menyeluruh sehingga diperlukan desain evaluasi pelatihan guru fisika profesional secara komprehensif.

\section{METODE PENELITIAN}

Penelitian ini merupakan penelitian deskriptif yang dilaksanakan dengan menggunakan metode studi pustaka terhadap berbagai sumber informasi ilmiah terpercaya dalam bentuk buku, jurnal, dan referensi lainnya. Penelitian ini dapat menghasilkan ulasan ilmiah dalam bentuk kajian teoritis yang dapat diterapkan dalam mengevaluasi kegiatan pelatihan yang mendukung upaya peningkatan profesionalitas guru fisika.

Data dalam penelitian diperoleh melalui dua sumber penelitian yaitu sumber penelitian primer dan sumber penelitian sekunder. Sumber data primer penelitian ini berupa buku-buku dan jurnal-jurnal yang memiliki kredibilitas tinggi. Sumber data penelitian sekunder berasal dari referensi data yang memberikan dukungan terhadap sejumlah data dan informasi yang diperoleh dari sumber data penelitian primer.

Data dalam penelitian ini dianalisis dengan berdasarkan kredibilitas sumber informasi. Teknik analisis data yang digunakan adalah teknik analisis isi (content analysis) dalam bentuk analisis ilmiah tentang isi pesan dari data yang disajikan.

\section{HASIL DAN PEMBAHASAN Model Logika Program Pelatihan Guru}

Model Logika secara luas digunakan dalam program perencanaan dan evaluasi. Evaluator dapat menggunakan model logika untuk membantu staf program mengartikulasikan dan membahas asumsi mereka tentang bagaimana program dapat mencapai tujuannya dan unsur-unsur penting untuk mengevaluasi program pada waktu yang ditetapkan. 
Model logika yang biasa digunakan pada umumnya mencakup empat tahap berikut (Rohmatulloh dkk, 2014)

1. Input: anggaran tahunan, staf fasilitas, peralatan, dan bahan-bahan yang diperlukan untuk menjalankan program.

2. Kegiatan: sesi mingguan, kurikulum, lokakarya, konferensi, perekrutan, layanan klinik, newsletter, pelatihan staf, semua komponen kunci dari program.
3. Output: jumlah peserta atau klien yang terlayani setiap minggu, jumlah pertemuan kelas, jam layanan langsung untuk setiap peserta, jumlah newsletter dan produk langsung program lainnya.

4. Hasil langsung, menengah, jangka panjang, dan paling akhir: tujuan longitudinal untuk perubahan peserta.

Model logika yang disusun untuk mengarahkan kegiatan evaluasi terhadap program pelatihan guru fisika profesional ditunjukkan pada Gambar 1.

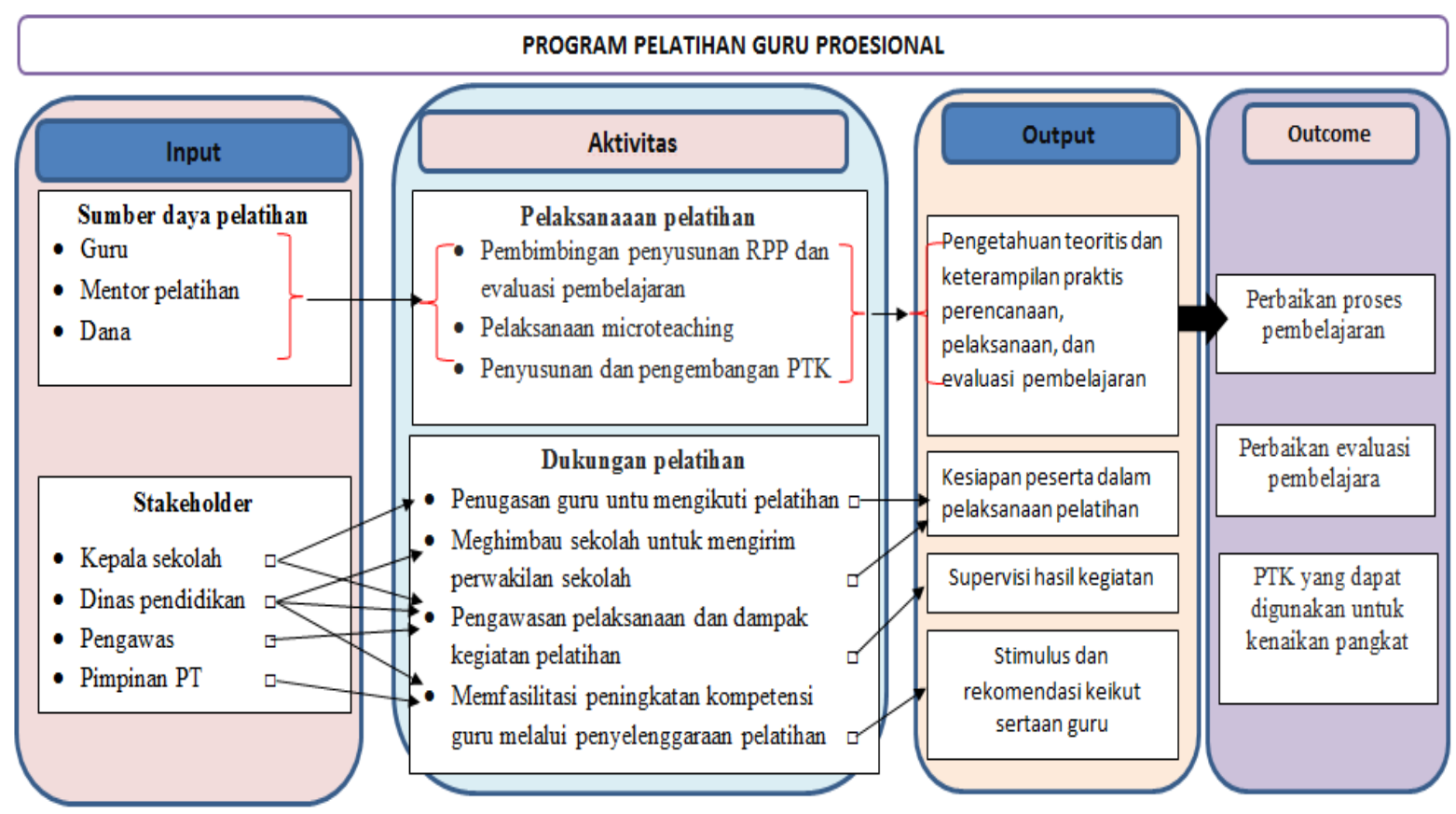

Gambar 1.Model Logika Program Pelatihan Guru Profesional

\section{Evaluasi Pelatihan Guru Fisika Profesional}

Evaluasi program merupakan sebuah rangkaian kegiatan yang dilakukan secara sengaja untuk melihat keberhasilan suatu program yang telah direncanakan (Arikunto, 1993: 297). Kirkpatrick (2006) menyatakan bahwa tujuan utama dalam evaluasi program adalah untuk menentukan tingkat efektifitas dari suatu program, sehingga ketika kegiatan evaluasi sudah dilakukan, diharapkan pihak-pihak yang bertanggung jawab dalam program tersebut dapat menjadikan hasil evaluasi sebagai dasar dalam membuat keputusan. Keputusan yang diambil dari hasil evaluasi program mengerucut pada pertimbangan apakah program tersebut berhasil atau tidak, dapat dilanjutkan atau dihentikan, serta dapat dijadikan pijakan untuk menyusun program lanjutan.

Model evaluasi program sudah banyak dikembangkan untuk memberikan keputusan yang baik dari hasil evaluasi program. Model evaluasi program disesuaikan dengan karakteristik program yang telah dievaluasi. Salah satu model evaluasi program yang berkembang adalah evaluasi empat level Kirkpatrick yang setiap levelnya merepresentasikan sebuah sekuen dari setiap tahapan untuk mengevaluasi program. Maksud dari 
sekuen adalah setiap level harus dilakukan secara bertahap. Hal ini penting untuk dilakukan karena setiap level memberikan dampak pada level berikutnya. Empat level tersebut adalah: Level 1- Reaction (Reaksi), Level 2Learning (Pembelajaran), Level 3Behavior (Perilaku), dan Level 4- Results (Hasil/Dampak).

\section{Level 1 - Reaction (Reaksi)}

Mengevaluasi reaksi sama halnya dengan mengukur tingkat kepuasan konsumen. Menurut Mc Lean \& Moss (2003), evaluasi di level satu biasa disebut dengan "happy face evaluation", dimana di level ini diukur reaksi dan kepuasan peserta terhadap program pelatihan. Tingkat kepuasan peserta dalam kegiatan pelatihan perlu diukur karena menyangkut motivasi mereka dalam belajar.

Evaluasi di level 1 tidak mengukur apa yang peserta telah pelajari, namun mengukur minat, motivasi, dan tingkat perhatian dari peserta pelatihan. Pentingnya mengukur reaksi didasarkan pada beberapa alasan, yaitu: untuk memberikan masukkan yang berharga kepada penyelenggara pelatihan dalam meningkatkan program pelatihan di masa datang; memberikan saran dan masukkan kepada pengajar mengenai tingkat efektifitas mereka dalam mengajar; dapat memberikan informasi kuantitatif kepada para pembuat keputusan terkait dengan pelaksanaan program pelatihan; serta dapat memberikan informasi kuantitatif kepada pengajar yang dapat digunakan sebagai dasar untuk membuat standar pengajaran untuk program yang akan datang.

Langkah-langkah dalam melakukan evaluasi di level-1 adalah:

a. Menentukan hal-hal yang dapat menginformasikan kepuasan peserta dalam mengikuti kegiatan pelatihan seperti fasilitas, jadwal, kualitas makanan, kualitas pengajar, kualitas diktat atau modul, kualitas media pembelajaran, strategi pembelajaran yang diterapkan pengajar, kesigapan dan keramahan panitia, serta informasi lainnya yang dibutuhkan.

b. Informasi-informasi tersebut kemudian dikemas dalam suatu format isian yang mudah dimengerti oleh subjek evaluasi, serta dapat menguantifikasi informasi-informasi tersebut. Kolom komentar dan saran perlu juga ditambahkan sebagai informasi tambahan.

c. Evaluasi di level ini perlu segera dilakukan, baik ketika kegiatan berlangsung, maupun setelah kegiatan pelatihan berakhir.

d. Melakukan tindakan yang tepat secara langsung dalam menyikapi hasil evaluasi.

\section{Level 2 - Learning (Pembelajaran)}

Evaluasi di level-2 berhubungan dengan pengukuran peningkatan kompetensi peserta, baik dari segi pengetahuan, keterampilan, dan sikap sesuai dengan tujuan diadakannya pelatihan. Pembelajaran didefinisikan sebagai prinsip, fakta-fakta, dan teknik yang dimengerti dan diserap oleh peserta. Adapun tujuan pelaksanaan evaluasi belajar di level-2 adalah untuk mengukur seberapa baik peserta program pelatihan mempelajari pengetahuan atau keterampilan yang disampaikan dalam kegiatan pengajaran. Berdasarkan definisi tersebut, mengukur pembelajaran merupakan kegiatan untuk menentukan satu hal atau beberapa hal yang berhubungan dengan tujuan pelatihan, seperti pengetahuan apa yang telah dipelajari, keterampilan apa yang telah dikembangkan atau ditingkatkan, dan sikap apa yang telah berubah.

Langkah-langkah dalam melaksanakan evaluasi di level-2, adalah:

a. Melakukan evaluasi terkait peningkatan pengetahuan, keterampilan, dan perubahan sikap sebelum dan sesudah pelatihan.

b. Menggunakan tes tertulis untuk mengukur pengetahuan dan sikap.

c. Menggunakan tes performa dalam mengukur keterampilan. 
d. Menggunakan hasil pengukuran tersebut untuk melakukan tindakan yang sesuai.

\section{Level 3 - Behavior (Perilaku)}

Perilaku dalam program pelatihan menurut Kirkpatrick

menggambarkan sejauh mana perubahan perilaku yang muncul karena peserta mengikuti program pelatihan. Evaluasi level-3 dilakukan untuk mengindikasikan sejauh mana materi dalam pelatihan diaplikasikan pada pekerjaan dan tempat kerja peserta (Steensma dkk., 2010). Evaluasi perilaku mengukur pengetahuan, keterampilan, atau sikap apa yang dipelajari untuk diaplikasikan atau dipindahkan pada pekerjaan.

Tujuan dilakukannya evaluasi di level 3 adalah untuk mengukur perubahan dalam perilaku kerja yang muncul karena guru tersebut mengikuti program pelatihan. Ada empat kondisi yang diperlukan untuk dapat mengaplikasikan perubahan perilaku tersebut, yaitu: seseorang harus mempunyai keinginan untuk berubah; seseorang harus tahu apa yang harus dilakukan dan bagaimana cara melakukan hal tersebut; seseorang harus bekerja dalam lingkungan kerja yang tepat; serta seseorang harus mendapatkan penghargaan karena dia berubah.

\section{Level 4 - Result (Hasil)}

Evaluasi hasil didefinisikan sebagai sebuah hasil akhir yang terjadi sebagai akibat peserta mengikuti program pelatihan. Evaluasi di level-4 bertujuan untuk mengetahui apakah program pelatihan bermanfaat dalam mencapai tujuan organisasi. Hubungan antara hasil positif yang diterima oleh lembaga dengan kegiatan pelatihan merupakan hal yang rumit, karena banyak aspek-aspek lain yang mempengaruhi hal tersebut dan pelatihan mungkin adalah salah satunya.

Dalam melakukan implementasi model evaluasi empat level, harus dilakukan secara sekuen, karena setiap level merupakan hal yang penting dan mempunyai dampak pada level selanjutnya. Sebagai contoh, apabila dilakukan evaluasi langsung di level-3 (tanpa melakukan evaluasi di level-2), ketika hasil evaluasi mengindikasikan bahwa hanya sedikit peserta yang perilakunya berubah sesuai dengan tujuan pelatihan, maka kesimpulan yang muncul adalah bahwa program pelatihan tidak bagus, sehingga tidak lagi dilanjutkan atau dilakukan modifikasi. Hal tersebut adalah tidak tepat, karena dalam menerapkan perubahan perilaku terdapat faktor-faktor lain yang mempengaruhi seperti kondisi tempat kerja dan pimpinan peserta pelatihan.

Faktor lain yang tidak kalah penting adalah dengan melihat hasil analisis evaluasi di level-2, sehingga dapat ditelusuri, apakah ketidakmampuan peserta dalam merubah perilakunya juga disebabkan oleh kurangnya pemahaman peserta terhadap materi. Alasan kurangnya peserta dalam memahami materi kemudian dapat juga ditelusuri dengan melihat hasil analisis peserta di level-1, apakah pemahaman materi yang kurang dari peserta disebabkan oleh ketidakpuasan peserta terhadap penyelenggaraan pelatihan atau karena kualitas pengajar yang kurang, sehingga peserta tidak mempunyai motivasi dalam belajar. Jadi dengan dilakukannya implementasi model empat level secara sekuen, terdapat ukuran lebih sebagai dasar analisis untuk menarik suatu kesimpulan.

Kegiatan evaluasi program pelatihan guru profesional akan dilakukan dalam tiga tahap, yaitu

\section{Desain Evaluasi}

Untuk mengevaluasi program pelatihan guru fisika profesional dapat digunakan model empat level yang dikembangkan oleh Kirkpatrick. Desain evaluasi program pelatihan guru fisika profesional ditunjukkan pada Tabel 1. 
Tabel 1. Desain Evaluasi Program Pelatihan Guru Profesional

\begin{tabular}{|c|c|c|c|c|c|c|}
\hline No & Tujuan Evaluasi & $\begin{array}{c}\text { Level } \\
\text { evaluasi }\end{array}$ & Data yang terkumpul & $\begin{array}{c}\text { Teknik } \\
\text { pengumpulan } \\
\text { data }\end{array}$ & $\begin{array}{l}\text { Sumber } \\
\text { informasi }\end{array}$ & $\begin{array}{c}\text { Instrumen yang } \\
\text { digunakan }\end{array}$ \\
\hline 1 & $\begin{array}{l}\text { Mendeskripsikan } \\
\text { keterlaksanaan } \\
\text { program pelatihan } \\
\text { guru profesional }\end{array}$ & $\begin{array}{c}1 \text { - } \\
\text { Reaction }\end{array}$ & $\begin{aligned} & \text { Kualitas pemateri } \\
& \text { Kesesuaian materi dengan } \\
& \text { kebutuhan dan tema } \\
& \text { Fasilitas dan pelayanan } \\
& \text { pelatihan yang diberikan } \\
& \text { Pengaturan acara }\end{aligned}$ & $\begin{array}{l}>\text { Pengisian angket } \\
>\text { Interview }\end{array}$ & $\begin{array}{l}\text { Peserta } \\
\text { pelatihan guru } \\
\text { profesional }\end{array}$ & $\begin{aligned}> & \text { Angket } \\
> & \text { Format } \\
& \text { wawancara }\end{aligned}$ \\
\hline 2 & $\begin{array}{l}\text { Mengidentifikasi } \\
\text { perubahan } \\
\text { kompetensi guru } \\
\text { dalam } \\
\text { melaksanakan } \\
\text { pembelajaran di } \\
\text { SD }\end{array}$ & $\stackrel{2-}{\text { Learning }}$ & $\begin{aligned} & \text { Pemahaman teoritis dan } \\
& \text { praktis terhadap materi: } \\
> & \text { Perencanaan pembelajaran } \\
> & \text { Pelaksanan pembelajaran } \\
> & \text { Evaluasi pembelajaran } \\
> & \text { Pengembangan PTK }\end{aligned}$ & $\begin{array}{l}>\text { Tes tertulis } \\
>\text { Observasi }\end{array}$ & $\begin{array}{l}\text { Peserta } \\
\text { pelatihan guru } \\
\text { profesional }\end{array}$ & $\begin{array}{l}\text { Pretest dan } \\
\text { postest } \\
>\text { Rubrik penilaian } \\
\text { kinerja }\end{array}$ \\
\hline 3 & $\begin{array}{l}\text { Mendeskripsikan } \\
\text { implementasi } \\
\text { hasil pelatihan } \\
\text { guru profesional di } \\
\text { lingkugan kerja }\end{array}$ & $\begin{array}{c}3- \\
\text { Behaviour }\end{array}$ & $\begin{array}{l}\text { Implementasi pengembangan } \\
\text { rencana, proses, dan evaluasi } \\
\text { pembelajaran serta PTK } \\
\text { Dukungan lingkugan } \\
\text { terhadap implementasi } \\
\text { pengembangan }\end{array}$ & $\begin{array}{l}>\text { Penilaian kinerja } \\
>\text { Studi dokumen }\end{array}$ & $\begin{aligned} & \text { Kepala } \\
& \text { sekolah } \\
> & \text { Pengawas }\end{aligned}$ & $\begin{array}{l}\text { Format penilaian } \\
\text { implementasi } \\
\text { pengembangan } \\
\text { proses dan } \\
\text { evaluasi } \\
\text { pembelajaran }\end{array}$ \\
\hline 4 & $\begin{array}{l}\text { Mengidentifikasi } \\
\text { dampak pelatihan } \\
\text { guru profesional } \\
\text { dalam } \\
\text { peningkatan } \\
\text { kinerja }\end{array}$ & $\begin{array}{c}4- \\
\text { Result }\end{array}$ & $\begin{array}{l}\text { Dampak pelatihan terhadap } \\
\text { kinerja guru } \\
\text { Dampak pelatihan terhadap } \\
\text { kualitas pembelajaran dan } \\
\text { evaluasi }\end{array}$ & $\begin{array}{l}>\text { Observasi } \\
>\text { Penilaian kinerja }\end{array}$ & $\begin{aligned} & \text { Kepala } \\
& \text { sekolah } \\
> & \text { Pengawas }\end{aligned}$ & $\begin{array}{l}\text { Format penilaian } \\
\text { kinerja guru } \\
\text { Format penilaiain } \\
\text { pengembangan } \\
\text { PTK }\end{array}$ \\
\hline
\end{tabular}


Model ini merupakan kerangka evaluasi klasik untuk menilai efektifitas pelatihan dalam konteks organisasi (Praslova, 2010). Model empat level Kirkpatrick merupakan model evaluasi yang secara luas diterima dan digunakan, karena sederhana, lengkap, jelas dan mudah untuk dilakukan. Model empat level mempunyai kemampuan dalam menyederhanakan proses evaluasi pelatihan yang kompleks, dengan dua cara, yaitu model empat level merepresentasikan pedoman langsung mengenai jenis pertanyaan yang harus ditanyakan dan kriteria yang mungkin sesuai, dan model tersebut mengurangi kebutuhan pengukuran dalam evaluasi pelatihan. Adapun

\section{Pengumpulan Data}

Pengumpulan data dalam evaluasi pelatihan guru profesional dapat dilaksanakan dalam kurun waktu satu semester terhitung sejak awal tahun ajaran. Data yang dikumpulkan meliputi data yang dibutuhkan dalam empat level evaluasi seperti yang ditunjukkan pada Tabel 1. Data tersebut akan memberikan gambaran bagaimana keberhasilan dari kegiatan pelatihan yang telah dilaksanakan sehingga dapat memberikan informasi dan memberikan pertimbangan kepada para stakeholder dalam memutuskan keberlanjutan program pelatihan pada tahun selanjutnya.

Pengambilan data dilaksanakan dengan tiga tahap evaluasi. Evalusi pada level 1 dan level 2 dilaksanakan pasca kegiatan pelatihan sebelum kegiatan penutupan. Evaluasi pada level 3 dilaksanakan pada pertengahan semester dan evaluasi pada level 4 dilaksanakan pada akhir semester.

\section{Teknik analisis data}

Data yang terkumpul dari empat level evaluasi pada kegiatan pelatihan guru profesional dapat dianalisis secara kualitatif untuk memberikan deskripsi menyeluruh tentang keberhasilan program dan dampak jangka panjang yang menjadi dasar dalam peningkatan kualitas kegiatan pelatihan. Hasil analisis data yang terkumpul akan menjadi bahan pertimbangan yang sangat bermanfaat bagi penyelenggara dan stakeholder yang berkepentingan berkaitan dengan keberlanjutan program pelatihan pada tahun selanjutnya.

\section{SIMPULAN}

Kegiatan evaluasi pelatihan guru fisika profesional dapat dilakukan dengan menggunakan model empat level Kirk Patrick yang meliputi level 1- reaction (reaksi), level 2- learning (pembelajaran), level 3- behavior (perilaku), dan level 4results (hasil/dampak). Evaluasi ini diharapkan dapat memberikan deskripsi keterlaksanaan pelatihan yang diukur berdasarkan tujuan pelaksanaan pelatihan guru. Hasil dari evaluasi ini dapat dimanfaatkan oleh pihak penyelenggara dan juga pihak-pihak terkait yang memang berkepentingan dan bertanggung jawab dalam upaya menjaga dan mengembangkan kompetensi guru profesional.

\section{REFERENSI}

Arikunto, S.(1993). Dasar-dasar Evaluasi Pendidikan. Jakarta: Bumi Aksara.

Awang, M. M., Jindal-Snape, D., \& Barber, T. (2013). A documentary analysis of the government's circulars on positive behaviour enhancement strategies. Asian Social Science, 9(5).

Aziz, F. (2012). Impact of faculty professional development program of HEC on teachers competencies and motivation at higher education level in Pakistan. Tesis tidak diterbitkan. University of the Punjab.

Budiman, D.M., Gumilar, S., \& Rizal, R. (2018). Focus, Explore, Reflect and Apply (FERA ) Learning Model : Developing Science Process Skills for Pre-Service Science Teachers. Tadris: Jurnal Keguruan dan Ilmu Tarbiyah, 3 (2).

Kemendikbud. (2015). Hasil Uji Kompetensi Guru Dijadikan Landasan Program Guru 
Pembelajar. Diakses
www.kemendikbud.go.id.

Kirkpatrick, D.L. \& Kirkpatrick J.D. (2006). Evaluating Training Program The Four Levels. San Fransisco: Berret-Kohler Publisher, Inc.

Mahmudah, I.R., Makiyah, Y.S., \& Sulistyaningsih, D. (2019). Profil Keterampilan Proses Sains (KPS) Siswa SMA di Kota Bandung. Diffraction: Journal for Physics Education and Applied Physics, 1(1).

Makiyah, Y.S, Malik, A., Susanti, E., \& Mahmudah, I.R. (2019). Higher Order Thinking Real and Virtual Laboratory (HOTRVL) untuk Meningkatkan Keterampilan Abad Ke-21 Mahasiswa Pendidikan Fisika. Diffraction: Journal for Physics Education and Applied Physics, 1(1).

Mc Lean, S., \& Moss, G. (2003). They're Happy, but Did They make a Difference? Applying Kirkpatrick's Framework to the Evaluation of a National Leadership Program. The Canadian Journal of Program Evaluation, 8(1).

Norlander, K.A. (2009). My life story A: School of education. Connecticut: University

Praslova, L. (2010). Adaptation of Kirkpatrick's four level model training criteria to assessment of learning outcomes and program evaluation in higher education. Educ Asse Eval Acc. 22 (215-225).

Rizal, R. (Oktober 2011). Recommended student's worksheets revision for increasing physics concept comprehension in discovery learning and interactive demonstration. The International Seminar Enhancing Science Teacher Profesionalism Through Physics Learning Innovation. Bandung.

Rizal, R. (2018). Implementasi Discovery Learning dalam Meningkatkan Pemahaman Konsep Listrik Dinamis. Jurnal siliwangi, 4(1).
Rizal, R. \& Irwan, M.R. (2019). Implementasi Discovery Learning untuk Meningkatkan Keterampilan Dasar Proses Sains Siswa SMA. JoTaLP: Journal of Teaching and Learning Physics, 4(1).

Rizal, R., Setiawan, W. \& Rusdiana, D. (2019). Digital Literacy of Preservice Science Teacher, Journal of Physics: Conference Series, 1157022058.

Rizal, R., Rusdiana, D., Setiawan, W. \& Siahaan, P. (2020). The Digital Literacy of The First Semester Students in Physics Education. Jurnal Pendidikan Fisika Universitas Muhammadiyah Makassar, 8(2).

Rizali, A. (2009). Dari Guru Konvensional menuju Guru Profesional. Jakarta: Grasindo.

Rohmatulloh \& Imam, M. (2014). Pengembangan Model Logika Evaluasi Program Pengembangan SDM Responsif Gender Bidang ESDM. Jurnal Teknik Industri, $15(2)$.

Susanti, E., Ratnawulan \& Kamus, Z. (2015). Pengaruh Penerapan LKPD Berbasis Discovery Learning Berbantuan Mind Map Terhadap Kompetensi Ipa Peserta Didik Kelas Vii Smpn 6 Bukittinggi. Pillar of Physics Education, 5.

Susanti, E., Maulidah, R. \& Makiyah, Y. S. (2019). Peran Guru Guru Fisika Di Era Revolusi Industri 4.0. Diffraction: Journal for Physics Education and Applied Physics, 1(1).

Sulistyaningsih, D., Ishafit, Mahmudah, I.R. \& Sujarwanto, E. (2019). Penentuan Koefisien Viskositas Air dengan Aliran Kapiler. Diffraction: Journal for Physics Education and Applied Physics, 1(1).

Zahri, C. H. (2009). Manajemen Sumber Daya Pendidikan. Yogyakarta: Pena Persada. 